\title{
De prudencia y ocasión: la historia como respuesta a los contrasentidos éticos de la razón moderna
}

\author{
On prudence and occasion: history as an answer to the ethical \\ contradiction of the modern reason
}

\author{
Aaron Grageda Bustamante \\ agrageda@sociales.uson.mx \\ Profesor titular \\ Universidad de Sonora \\ Blvd. Luis Encinas y Rosales, s.n. - Edificio 101 - Tercer Piso - Col. Centro \\ 83000 - Sonora \\ México
}

\begin{abstract}
Resumen
El presente artículo tiene como punto de partida la crítica contemporánea al conocimiento histórico, sobre todo en cuanto al hecho de que el mismo posee una especialización y fragmentación tales que lo despojan de toda utilidad práctica. Lo anterior está asociado con la crítica heideggeriana al pensamiento de Kant, realizada durante sus años de trabajo en la Universidad de Marburgo. La tesis fundamental que sustenta esta contribución es que tal condición del conocimiento histórico es manifestación de la racionalidad moderna y que la historia, en el pasado, como lo demuestra el culto antiguo de la prudencia, pudo reconciliar el pragmatismo con el saber experto. El enfoque con que se aborda este artículo se mueve de la historia intelectual a la cultural y se fundamenta lo mismo en la tradición pictórica europea que en la escritura literaria e histórica.
\end{abstract}

\section{Palabras clave}

Conocimiento histórico; Sentido; Modernidad.

\begin{abstract}
This essay takes as its starting point the contemporary criticism of historical knowledge, specially the fact that it has a specialized and fragmented character which deprives it of any practical usefulness. This is associated with Heidegger's criticism of Kant's theory, developed at the University of Marburg. The main assumption underlying this contribution is that this condition of historical knowledge is a manifestation of modern rationality. Yet history in the past was able to conciliate pragmatism with specialized knowledge, as evidenced by the ancient cult of prudence. Regarding methodology, this article thus, combines approaches from intellectual history with cultural history bringing in elements from European pictorial and literary traditions.
\end{abstract}

\section{Keywords}

Historical knowledge; Meaning; Modernity. 
Es imposible en nuestros días hacer oídos sordos a la crítica surgida al interior de las ciencias humanas, según la cual el grado de especialización, fragmentación y sofisticación que dichas ciencias han adquirido las últimas décadas no se corresponde con su capacidad de elaborar soluciones instrumentales a problemas socialmente relevantes (BREWER 1999, p. 327). Aunque existe el convencimiento de que "el actual fundamento racional de las disciplinas ya no tiene mucho sentido" (WALLERSTEIN 1996, p. 5), los esfuerzos realizados hasta ahora para contrarrestarlo no han dejado satisfechos a todos (HIRSCH 2008, p. 20).

A pesar de que se conocen innumerables intentos de integración disciplinaria (KARLQVIST 1999, p. 379), se ha extendido cada vez más en el pensamiento social un sentimiento de vértigo, de un vacío creado por una institución científica superespecializada que existe para sí misma y para la reproducción de sus intereses, independientemente de (e indiferente a) las necesidades humanas que deberían ser la razón de su existencia (GIBBONS 1997).

Se tratará de mostrar, en la presente contribución, cómo en una de las primeras críticas a la Modernidad (y sobre todo en torno a su modo dominante de conocimiento), fue vislumbrado ese contrasentido básico del racionalismo contemporáneo. Se pondrá énfasis, especialmente, en el funcionamiento de la historia como disciplina que una vez fue capaz de brindar una solución al dilema ético del solipsismo científico, ese mismo que empaña hoy el resplandor que otrora caracterizara a muchas disciplinas sociales.

Por sorprendente que parezca - y ello representa la tesis fundamental de este trabajo - , la historia articuló durante mucho tiempo los elementos básicos de un paradigma de conocimiento social, unificador y pragmático, materializado en el cultivo de la prudencia, que, funcionando como forma práctica de orientación para la vida, fue rebasado paulatinamente por el predominio del cartesianismo, teniendo sin embargo la virtud de poner al hombre, en su actuar y padecer en el mundo, como la finalidad última y preponderante de la reflexión científica.

Funcionando de forma secular y sistemática, ese modelo de construcción de conocimiento social, logró gozar hasta el siglo XVIII de un reconocimiento tal que popularizó ampliamente a la historia, consolidándola en distintas épocas y culturas como saber fundamental en los más diversos campos de la creación intelectual y artística de Europa. Aunque hasta hoy se ha teorizado poco en torno a ello, la tradición y presupuestos operativos que por entonces dieron vida a esa forma de conocimiento fue tal que, como se mostrará, poco faltó para que con ella se reescribiera la filosofía de la ciencia del siglo XX.

\section{A la vera del Lahn}

Algo debió de existir en la Universidad de Marburgo que capturó fuertemente la atención de Martin Heidegger. Quizá fue la atmósfera romántica de una pequeña ciudad, el cauce de su río, o el bosque de los alrededores, por donde frecuentemente se veía a Heidegger hacer sus paseos al caer la tarde. Pero también pudo haber sido el ambiente de una universidad que, en ese entonces, contaba con no más de tres mil estudiantes, que, en pleno auge de la República 
de Weimar, preferían entregarse más a los concursos de esgrima que a recordar los amargos días de la Primera Guerra Mundial.

Los años de 1923 a 1928 en Marburgo fueron, en palabras del propio filósofo, los que más disfrutó de toda su carrera docente (HIRSCH 1979, p. 336). Heidegger fue llevado por entonces a la Universidad por su colega Paul Natorp (BIEMEL 1973, p. 33). En esa época, la institución gozaba de reputación nacional por el prestigio de su escuela neokantiana y por el reconocimiento del departamento de Religión, que contaba con algunos de los más importantes teólogos del país.

La estancia de Heidegger en Marburgo es tan importante para la crítica de la Modernidad como desconocida es para la historiografía. De esa época data su productiva relación intelectual con Eduard Spranger, un connotado psicólogo de la misma universidad, a quien el filósofo llegó a citar años más tarde en su más famosa obra, al abordar lo concerniente a la "constitución del entendimiento histórico" (BIEMEL 1973, p. 394). Por entonces, como se mostrará, Heidegger había repasado ya durante varios años algunos aspectos de la teoría de la historia que posteriormente le serían de utilidad para fundamentar su propia orientación fenomenológica.

En 1926, Heidegger, interesado en la comprensión histórica, ofreció un seminario en el que expuso la obra de Johan Gustav Droysen, Historik, al escrutinio de su crítica filosófica. En un ensayo elaborado años antes, el filósofo había reflexionado sobre ese mismo tema y llegado a la conclusión de que

tal vez, el mérito más grande de la escuela crítica en las ciencias históricas, por lo menos el más significativo en relación con los métodos, es haber hecho claro finalmente que la fundación de nuestros estudios es la investigación de las fuentes desde las cuales aprendemos; y con ello la relación de la historia con el pasado ha alcanzado el punto en que es científicamente importante (KLOSTERMANN 1972, p. 370).

Droysen fue de importancia para Heidegger, porque dicho historiador elaboró también una biografía de Yorck von Wartenburg, cuya correspondencia con Dilthey fue discutida ampliamente por el filósofo en El ser $y$ el tiempo, obra aparecida un año después de impartido dicho seminario. El distanciamiento de Heidegger con respecto a Droysen se deberá, no obstante, como ha sido propuesto, a que el historiador define la historia como una extensión del dominio ético, "suposición que Heidegger no compartió y la cual carece para él de toda prueba" (HIRSCH 1979, p. 341).

Fue, sin embargo, otra vertiente de la reflexión historiográfica la que causará en Heidegger mayor entusiasmo, una que coincidió con el momento mismo de su llegada a la vera del Lahn y de su incorporación a la Universidad de Marburgo. Precisamente en el verano de 1923, Martin Heidegger impartió un seminario que llamó "Sobre la frónesis", el cual tuvo como objetivo discutir "otros tipos de conocimiento".

La concepción misma del seminario puede entenderse, más que como provocación, como una de las primeras críticas a uno de los conceptos 
fundamentales de la Modernidad. Representa particularmente una toma de posición en ciernes, contra el pensamiento guiado por la idea de una razón fría y abstracta, producto de la Ilustración y esencia de la conciencia moderna. La "frónesis", es decir, la razón práctica (que Aristóteles diferencia en la Ética a Nicómano de "episteme", la razón científica, y de "techné", vinculada con la creación), será celebrada a lo largo de su crítica como la vía de la acción, propiciadora de un cambio exhaustivo, pragmático, fundamentado en experiencias (Arist. Nich. Eth.).

Heidegger percibió en la frónesis una forma de racionalidad que no involucraba nada de lo que la razón, en su sentido contemporáneo, implicaba. La frónesis es práctica, orientada a la acción, y no de naturaleza teórico-especulativa; se basaba también, de acuerdo a Aristóteles, en la experiencia, no surgía (solamente) de las deducciones abstractas. La frónesis podía considerarse una virtud común al género humano y no solamente de aquellos preocupados en cultivar la razón científica.

Visto desde esa perspectiva, el seminario de Heidegger representó una crítica al corazón mismo de la tradición kantiana, a saber, a la "aporía de la razón". Kant, como se sabe, realizó la distinción entre dos tipos de razón. La primera es pura, perteneciente a la ciencia y la lógica; la otra es "pura razón práctica", característica de campos como los de la moral y las leyes, y es condición de posibilidad de la acción moral (2003, p. 41).

La pregunta que surge a partir de ese orden de ideas es: ¿qué vínculo 82 material pudo haber existido entre la frónesis aristotélica, la historia y la aplicabilidad del conocimiento humano? Sobre todo, ¿qué llevó a Heidegger -como lo sugiere su seminario sobre la frónesis- a buscar formas de conocimiento alternativos que sortearan los contrasentidos de una razón pura que se distancia de los intereses del sujeto?

Hoy se conocen los alcances de una tradición filosófica que, iniciando en el Imperio Romano y floreciendo en la etapa final de la Edad Media, resolvió la contradicción entre frónesis y episteme y fue incluso capaz de derivar la primera de la última sin necesidad de poner a ambas en un plano de igualdad. Esa tradición epistemológica se hace manifiesta sobre todo en la recepción clásica y medieval de los textos platónicos y aristotélicos. Sus fundamentos no se basan en la ética, sino en un concepto diferente de la función y esencia primaria de la razón, de la cual la razón práctica llegó a ser solo una expresión entre otras. Esta tradición conduce a la razón (o la racionalidad) por un camino distinto al que popularizaron los ilustrados y sus precursores (es decir, el de un proceso fundamentalmente abstracto-estructural) e incorpora incluso los criterios contenidos en cada forma de conocimiento como parte del objeto mismo.

\section{Una forma práctica de conocimiento}

En estricto sentido cronológico, es en Fedón, uno de los diálogos platónicos, donde por primera vez se hace uso del concepto "frónesis" ( en la doble acepción de "sabiduría", aunque (dependiendo de las traducciones) también de "inteligencia". "La sabiduría es", declara Sócrates, "la única moneda 
de buena ley, y por ella es preciso cambiar todas las demás cosas. Con ella se compra todo y se tiene todo: fortaleza, templanza, justicia" (PLATO 1861, p. 69a).

Sin embargo, la definición básica de "frónesis", así como la reflexión clásica que la hizo visible en la tradición filosófica, fue desarrollada posteriormente por Aristóteles, quien en sus lecciones de ética la emplea en profundidad, diferenciándola, tanto de "ciencia" (que se caracterizaría por la demostración), como de "arte" (fundamentado en la creación) (HANEY 1999, p. 32). La "prudencia", término elegido para traducir el concepto de frónesis, lo mismo en latín que en las principales lenguas europeas (EBERT 2006, p. 165), "no es ciencia porque las materias de conducta admiten variación; y no es arte, porque hacer y realizar son genéricamente distintos. Queda por lo tanto", afirma Aristóteles (Arist. Nich.Eth. 6.5.1140b), que la misma es "una verdad sujeta a cualidades racionales, que se ocupa de la acción respecto a las cosas que son buenas o malas para los seres humanos". De esa manera, en Aristóteles, se definió a la prudencia, no solo como virtud superior, sino como "capacidad de juicio práctico moral" (HÖFFE 1998, p. 42), orientado a lograr "una buena vida en lo general".

Si bien la prudencia tuvo en la frónesis aristotélica su lugar central, también lo tuvo en la primera etapa de la filosofía cristiana, la misma que hubo de desarrollarse independientemente de la influencia aristotélica (PAYER 1979, p. 55). El tratamiento de la frónesis, elaborado en el sexto libro de la Ética a Nicómaco, no fue asequible como traducción en Occidente sino hasta mediados del siglo XIII; sin embargo, una rica herencia de especulación filosófica comenzó a difundirla como tema en una época muy temprana (GAUTHIER; JOLIF 1970, p. 111).

Ha sido sugerido que fueron dos períodos los que contribuyeron en la Edad Media al desarrollo sistemático de la prudencia. El primero queda definido por los debates gestados en el marco de la rivalidad con su par conceptual: la discretio, en función de los cuales, de forma gradual hasta el siglo XII, se realiza la entronización de la prudencia como virtud cardinal central (DINGJAN 1967). Un segundo período, sin embargo, rechaza la naturaleza de la prudencia como virtud. Como se hace explícito en las reflexiones de Abelardo, toda vez que a la misma se le restituye como forma de conocimiento, no se le otorgó un carácter moral ni, por lo tanto, una dimensión virtuosa (PAYER 1979, p. 57). La interpretación clásica al respecto afirma que la disyuntiva entre moral y conocimiento que caracterizó a dicho período se resolvió al asociar la prudencia con el uso responsable de la voluntad, un proceso en el que sí se le confería un carácter moral (LOTTIN 1932, p. 280). De esa forma, la prudencia continuaba siendo conocimiento, pero uno de tal naturaleza que le permitía volverse virtud si se asociaba con la voluntad.

Ambos procesos se suceden de forma previa a la recepción del sexto libro de la Ética de Aristóteles, momento a partir del cual se establecerá en definitiva la definición básica del concepto. Desde entonces, la prudencia aristotélica será adoptada de forma unánime e influirá en las discusiones posteriores (PAYER 1979, p. 56). Su presencia es visible en los trabajos de una amplia gama de filósofos del pensamiento cristiano previos a Tomás de Aquino. 
Guillermo de Auxerre es quien inaugura con su obra Summa aurea esa reflexión. Es el primer autor del siglo XIII que incorpora la discusión de la virtud de la prudencia en un trabajo teológico más amplio, centrándose predominantemente en la cuestión de su cientificidad y, sobre todo, vinculándola por primera vez con los postulados de la ley natural. Aunque sus escritos no hayan alcanzado la constitución de un tratado estructural sobre la prudencia y su forma de adquisición, echó las semillas de la crítica en un campo fértil (PAYER 1979 , p. 59), como se mostrará a continuación.

Es Felipe el Canciller, teólogo y lírico francés, quien realizará un tratado estructural sobre la prudencia a lo largo de Summa bono, su libro más influyente. En su proposición introduce el concepto de recto juicio, que se materializa en la razón humana; de ahí que, siguiendo a Harlardus, obispo de Dorchester, proceda a definir: "Ad illam autem qua est: 'prudentia est divinae et positivae iustitiae " " (CHANCELLOR 1985, p. 135vb). Sin embargo, solo posteriormente, con Albertus Magnus, la prudencia llegará a obtener una definición y fundamentación sin precedentes en la práctica filosófica de Occidente.

En De bono, Albertus Magnus desarrolla un extenso tratado de las virtudes cardinales en lo general, dedicando especial interés a la prudencia. Poco después, al darse a conocer en la época la primera traducción de la Ética de Aristóteles (PAYER 1979, p. 62), dicho teólogo complementará la definición original. La contribución de ese personaje consistió en establecer una relación estrecha entre la prudencia y los principios fundamentales del derecho natural. Éstos últimos son de hecho derivaciones, tanto de la prudencia como de la inteligencia práctica, ambas sintetizadas en un almacén interior de valores morales de corte universal al género humano, denominado "sindéresis" (MCQUADE 2000, p. 234). De esa manera, para el obispo de Colonia, "prudentia est habitus cum ratione vera circa humana bona activus" (MAGNUS 1968-1972, p. 1140b20).

En un orden semejante de ideas, Tomás de Aquino señala que los principios fundamentales de la acción humana son los preceptos del derecho natural, que son conocidos a su vez de forma natural por todos los hombres. El concepto clave en el análisis tomista de la prudencia fue la noción de applicatio (PAYER 1979, p. 67). Una de las funciones básicas de la prudencia en la filosofía de Aquino es, por lo tanto, aplicar los principios prácticos del intelecto a circunstancias concretas de la acción humana, porque, como llegó a consignar, "Prudentia est recta ratio agibilium" (AQUIN 2013, p. 47).

De esa manera, en la recepción medieval son definidos dos aspectos centrales de la prudencia y su enseñanza; a saber: "la importancia central de la razón y el conocimiento como sus atributos fundamentales, vinculados a la vida moral responsable de la persona"; así como buscar "respuesta a la necesidad de establecer criterios y estándares para el juicio prudente" (PAYER 1979, p. 70).

\section{Más allá de la elocuencia}

Una tendencia intelectual igualmente rica que la aristotélica, solo que de extracción latina, brindó, en lo referente al estudio de la prudencia, los elementos que a la postre condicionarían el desarrollo del Humanismo y el 
prolífico uso y divulgación del concepto. En esa línea, la centralidad de la herencia ciceroniana es evidente.

Investigaciones relativas a este tema apuntan a que "los escritos de Cicerón sustentaron las primeras definiciones de prudencia en Occidente, antes de la recuperación de los textos aristotélicos en el siglo XII" (CAPE JR. 2003, p. 36). Esto último es particularmente visible en el tratamiento de la prudencia como virtud cardinal. Aunque existen dudas al respecto (WESTBERG 1994), se ha llegado a afirmar que, de las tres obras ciceronianas fundamentales, "Tomás de Aquino desarrolló su concepto de prudencia, añadiendo solamente poco de Aristóteles" (RAND 1946).

El texto clave en el que Cicerón explica su entendimiento de la prudencia es De oratore, que desarrolla en su etapa de madurez personal. Se ha informado que la Edad Media conoció, citó y divulgó la lectura de dicho libro solo en una versión mutilada, hasta que llegó a descubrirse en Lodi, en 1422, un ejemplar íntegro del mismo (WINTERBOTTOM 1983, p. 102-109). Ese acontecimiento fue fundamental para el desarrollo intelectual del Quattrocento e influenció de manera determinante el posterior movimiento renacentista.

La prudencia como concepto no estaba claramente definida en la tradición romana en la época de Cicerón (CAPE JR. 2003, p. 37). No obstante, el uso de la voz "prudentia" es documentable desde la época clásica en obras como las de Catón el Viejo, Enodio y Livio. No existe sin embargo, antes de que Cicerón la estableciera, una relación de igualdad entre frónesis y prudencia, lo cual surgió, al parecer, durante el proceso cultural de helenización que vivió Roma en la etapa tardía de la República, impulsado por la recepción de los escritos ciceronianos.

Es en De oficiis donde Cicerón iguala la prudencia al concepto de sapiencia, que poseía estricta naturaleza epistemológica. Sin embargo, como ha sido sugerido, el objetivo de su obra "no es articular una teoría comprensiva de la prudencia", tal como lo hizo Aristóteles, sino "proveer ejemplos de viri prudentes para el debate intelectual, asociando en consecuencia la prudencia con la retórica y la política" (CAPE JR. 2003, p. 39). De esa manera, como escéptico, Cicerón elaboró diálogos que tuvieron como escritura una manifiesta dimensión literaria, procurando así una forma de acción política y "proveyendo un modelo de la práctica de la prudencia".

Respecto a los escritos platónicos, Cicerón toma distancia, pues define la prudencia como una de las cuatro virtudes cardinales, ubicándola en relación de superioridad respecto a la fortaleza, la templanza y la justicia. El dictum clásico ciceroniano define la prudencia humana como "el conocimiento de las cosas que son buenas, malas, o ni lo uno ni lo otro". "Sus partes son", afirma (Cic. De inv. 53-160), "la memoria, la inteligencia y la previsión". De esa manera, como factor de diferenciación, se ha destacado que "Cicerón vierte la filosofía griega en la enseñanza de la retórica" (CAPE JR. 2003, p. 40).

Precisamente, ese fue el aspecto que otorgó al concepto ciceroniano de prudencia sus rasgos más significativos y duraderos. Así: 1) La prudencia se convierte en factor fundamental de la educación del doctus orator; 2) Se reconoce en ella la influencia determinante de los filósofos griegos Sócrates, Platón y Aristóteles; 3 ) Se consolida la supremacía de la vida activa frente a la vida contemplativa; y 4) La escritura se acredita como forma de actividad 
política e intelectual que tiene como fin el bien del estado. Sentadas esas bases, la prudencia estuvo en condiciones de difundirse y ser productiva en la recepción europea posterior. Con Séneca y Tácito, por ejemplo, se convirtió en "el medio para acomodarse en las condiciones del régimen político imperante" (CAPE JR. 2003, p. 61), así como influyó posteriormente en el movimiento estoico que le precedió (LUCKNER 2005, p. 103).

En esas circunstancias, los verdaderos beneficiarios de los aportes ciceronianos no fueron los romanos contemporáneos, sino los precursores del Renacimiento y, particularmente, los humanistas. La riqueza de su herencia intelectual fue visible en la recepción de las cuatro virtudes cardinales, de la cual la prudencia fue eje articulador hasta bien entrado el siglo XVIII. El conocimiento procurado por ella se volvió atributo del hombre ideal: pragmático, decoroso, responsable y con amplia participación en la vida cívica; capaz, tanto de escribir, como de actuar ante la ocasión. En pocas palabras, nutrió el ideal de un hombre guiado por un entendimiento de la razón, que reconciliaba el saber con los fines de su humanidad misma.

Con el transcurso del tiempo, la prudencia logró ser más que reflexión filosófica abstracta. La misma se materializó en múltiples expresiones, a lo largo y ancho de las diferentes regiones del continente, de forma casi simultánea a la crítica filosófica. A continuación, sin un ánimo comprensivo, se muestra ese hecho, describiéndose brevemente su influencia, tanto en la pintura, como en la plástica.

\section{La prudencia y el dominio pictórico europeo}

Una de las primeras representaciones de la prudencia en la tradición pictórica de Europa se encuentra en la capilla degli Scrovegni en Padua. Reconocida como obra original de Giotto de Bordone, elaborada hacia 1306 (GUILLAUD 1988), la imagen muestra los atributos básicos de la imagen de la prudencia, mismos que se mantendrán a la postre invariables; a saber: la asociación del concepto con la imagen de la mujer y el uso del espejo como representación del autoconocimiento.

Imagen 1:

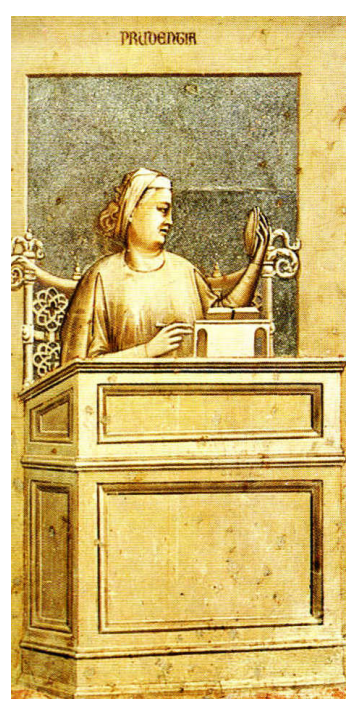

Giotto de Bordone. Prudentia (ca. 1306). Alegorías de las virtudes y los vicios.

Frescos de la capilla degli Scrovegni, Padua, Italia. 
La mujer como personificación de la prudencia deviene natural, no solo por el hecho de que se trata de simbolizar una virtud o una cualidad, sino también porque es femenino el género de la raíz latina de la que deriva "prudencia" como expresión, a saber, de la palabra providentia, entendida en su sentido básico como la capacidad de prever. Por su parte, el espejo aparece como el instrumento de reflexión por excelencia.

Giotto, no solamente es celebrado como el máximo innovador del sentido del espacio en su época, sino también como artista precursor del Renacimiento en el campo de la pintura (EDGERTON 2003, p. 8). Sin embargo, después de él vendrán una serie artistas que otorgarán a la representación de la prudencia una serie de atributos que la acercarán de forma definitiva, tanto a la historia, como al culto del conocimiento práctico. Entre ellos, se destaca Piero del Pollaiuolo.

Nacido hacia 1443 en Florencia, ese pintor, procedente de una familia de grabadores, colaboró con su hermano durante su etapa juvenil, empleándose por ejemplo en las tareas de ilustración del Hércules del Palazzo de Medici. Posteriormente, hacia 1489, pasó a ocuparse en Roma del cultivo de la pintura, dejando en su ciudad natal testimonio pictórico de las siete virtudes.

Imagen 2:

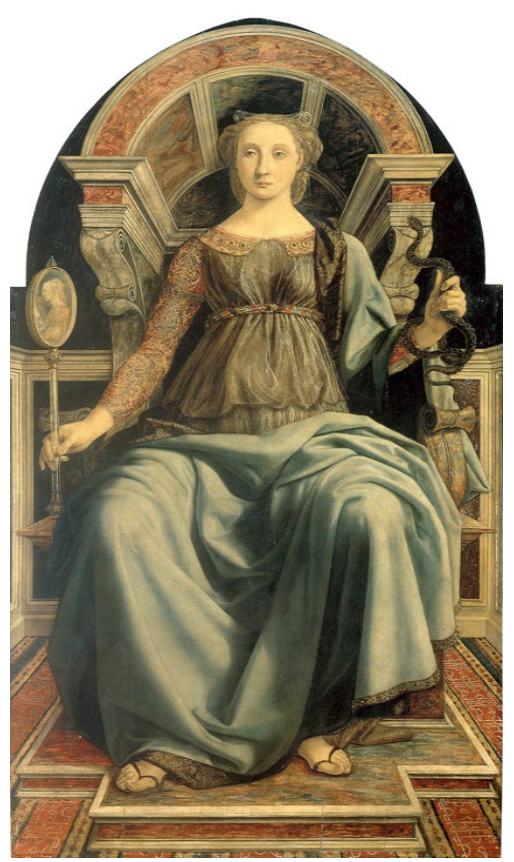

Piero de Pollaiuolo, Prudentia (ca. 1469-1470). Retablo de las siete virtudes. Galleria degli Uffizi, Florencia, Italia.

En la representación que llevó a cabo, como se muestra anteriormente, está presente la imagen de la serpiente como alegoría de los atributos contrarios a la previsión, sujetos por la prudencia. Esa adición, dicho sea de paso, tuvo como antecedente una imagen de la prudencia en la que Apollonio di Giovanni, pintor y miniaturista contemporáneo a Pollaiuolo (CALLMANN 1974), hacia 1465, introdujo en un panel que remata el extremo de un cofre, un cuerno en vez de una serpiente, empleado en alegoría a "La templanza de Escipión". 
Diez años después, en un altorrelieve elaborado en terracota por Andrea della Robbia, se introduce una tercera característica decisiva y duradera: la imagen bifronte de la representación de la prudencia. Este hecho, en pleno Renacimiento, remite a un entendimiento más ciceroniano que aristotélico de la prudencia y adjudica al conocimiento del pasado la función de ser la operación fundamental para procurar el saber. El rostro joven de la prudencia mira, en la representación de della Robbia, hacia el pasado, a lo sucedido, a la historia, con cuyo conocimiento puede anticiparse el porvenir, como lo hace el anciano, capaz de advertir lo venidero. Tres de los más célebres pintores de la época reproducirán a su manera ese mismo rasgo.

El primero de ellos es el pintor, teórico y matemático alemán Albrecht Dürer, representante del Renacimiento en la Europa del norte, quien hacia 1494 realiza una serie de dibujos y bocetos, de los cuales se destacan representaciones de pecados, virtudes y temores. Entre ellos, la prudencia, portando un compás graduado en la mano (lo que rememora la mesura), fue confeccionada con el espejo y el rostro bifronte, pero, que en vez de con la serpiente, la intemperancia es representada como quimera a sus pies.

Imagen 3:
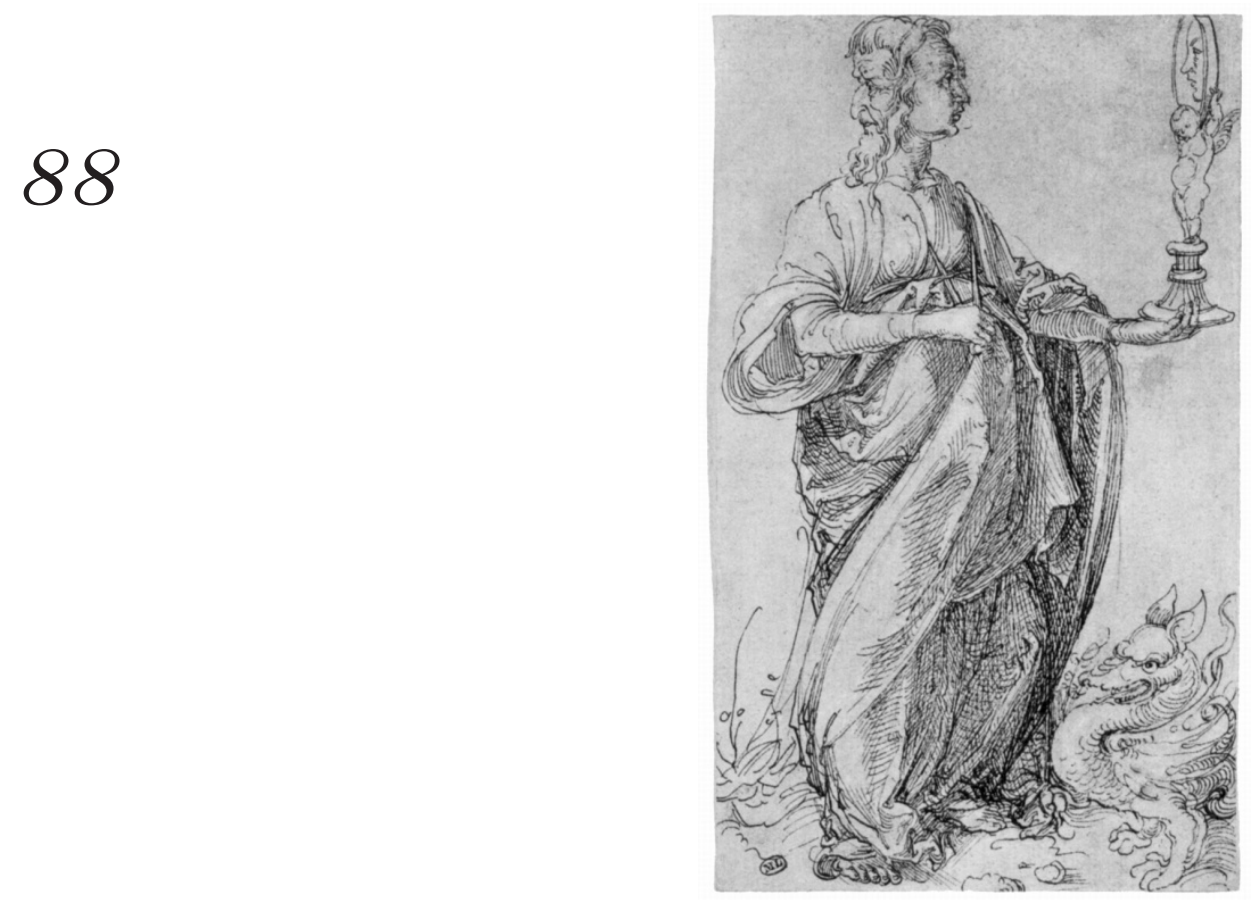

Albrecht Dürer. Prudentia (ca. 1494). Pluma y tinta en papel.

París, Museo del Louvre, Cabinet des Dessins.

Poco tiempo después, como segundo caso emblemático, en los frescos confeccionados en el Vaticano, particularmente en uno que compone la Stanza della segnatura, realizado entre 1508 y 1511, Raffaello Sanzio dejó testimonio de la importancia del pasado en el conocimiento de lo contingente y lo venidero. El rostro juvenil de la prudencia que confeccionó se reconoce en el espejo al mirar el pasado, en tanto que la experiencia, como rostro en la nuca, dirige su mirada hacia el futuro. 
Imagen 4:

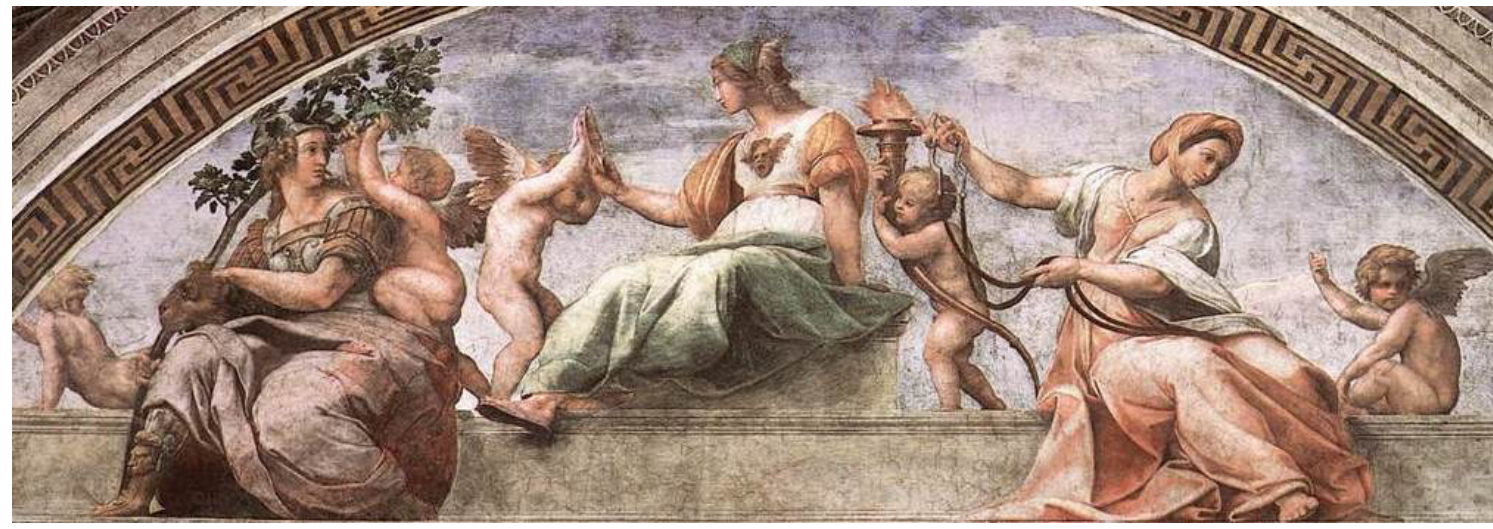

Raffaello Sanzio. Le Virtù. (ca. 1511).

Stanza della segnatura. Museo del Vaticano, Italia.

También Tiziano fue contagiado del entusiasmo por celebrar el conocimiento práctico. En la plasticidad de su interpretación de la prudencia, otorgó al pasado un lugar preponderante. Entre 1565 y 1570 concluyó un autorretrato, realizado en una etapa de su vida marcado visiblemente por la edad y en el que se representa junto a la figura adulta de su hijo que corona el centro de la pintura. A la derecha posa el rostro juvenil de un joven pariente suyo (ZIRPOLO 2005, p. 69). Esta pintura llegó a conocerse como "Alegoría del tiempo guiado por la prudencia", temática relacionada con las tres épocas del hombre. En la inscripción latina que a manera de fondo remata la obra, se consigna que el presente actúa prudente al informarse del pasado, desde donde se escudriña la acción del futuro.

\section{Imagen 5:}

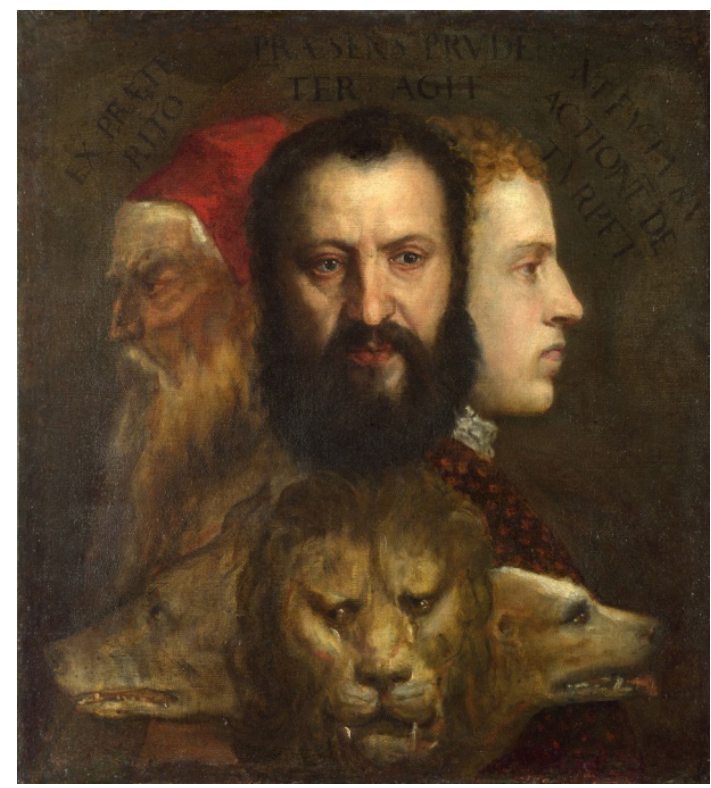

Tiziano Vecellio (ca. 1565-1570). Alegoría de la prudencia.

Galería Nacional de Londres, Inglaterra. 
Se ha sugerido que dicha ilustración de Tiziano da cuenta de un sistema de conocimiento en el que la prudencia operó teniendo a la historia como eje articulador de tres elementos: "la memoria, que recuerda y aprende del pasado; la inteligencia, que juzga en y actúa para el presente; y la previsión, que anticipa y previene para o contra lo futuro" (PANOSFKY 1955, p. 149-150).

En una referencia clásica de los estudios iconográficos de la pintura europea, se afirma que, hacia 1559, Pieter Brueghel el Viejo, había concluido ya "Las siete virtudes del mundo" (STRIDBECK 1956, p. 126). En dicho grabado, el artista dejó testimonio de la prudencia como modelo de conocimiento, capaz de articular, para beneficio humano, las tres dimensiones temporales. Si bien añadió a su representación otros elementos emblemáticos a los definidos hasta entonces (un colador y un sarcófago como símbolos del discernimiento y de la finitud, respectivamente), tales adiciones fueron subordinadas al mismo fin de la posesión práctica del conocimiento, es decir, celebrar un saber práctico orientado a la actuación y a la anticipación de las acciones en el mundo de la experiencia.

La representación de la prudencia se volvió, así, entre pintores y grabadores de la talla de Hans Baldung, Cesare Ripa, Hans Collaert y muchos otros, un factor de identificación común capaz de trascender barreras geográficas, artísticas y lingüísticas al interior de Europa. Su presencia generalizada da cuenta de la popularidad que alcanzó ese modelo de construcción de conocimiento fundamentado en el raciocinio y que otorgaba a la experiencia ( $y$, por lo tanto, a la historia) un sentido de utilidad práctica respecto a las circunstancias del presente y del futuro.

Cuando, hacia 1593, el pintor holandés Hendrik Goltzius realiza su representación de la prudencia, reafirma ese hecho, pues consigna que el viento del pasado es fundamento del cauto y de la sagacidad en el presente. En la "Alegoría de la prudencia" de Simón Vouet, confeccionada hacia 1645, el viejo Cronos, con su reloj de arena y su hoz, se encuentra postrado a sus pies. Sin embargo, nadie mejor que su contemporáneo Alessandro Turchi supo otorgar a la historia la centralidad que poseyó como engrane del esquema cognoscitivo antes descrito. Turchi coloca a la historia en el centro, flanqueada por la filosofía y la prudencia, encargadas de despertar en la mente el deseo de conocimiento.

\section{A la ocasión la pintan calva}

La efervescencia que trajo consigo esa forma práctica de raciocinio y su representación visual no excluyó las reflexiones sistemáticas del pensamiento filosófico y literario. Intelectuales de la primera etapa del Renacimiento, como Coluccio Salutati, discurrieron ampliamente acerca de la relación entre la memoria y prudencia, lo mismo que en torno a las ventajas de la vida activa frente a la contemplativa.

En el capítulo veintitrés de su obra De nobilitate legum et medicinae, escrita hacia 1399, Salutati señala incluso que la memoria, más que la prudencia, es la que gobierna la acción, siendo la voluntad el motor de las demás facultades de la mente (ZIRPOLO 2005, p. 70). Con De prudentia, Giovanni Pontano continuará esa misma crítica hacia finales del siglo XV. Sin embargo, la popularidad de 
la prudencia como sistema de comprensión fundamentado en la experiencia adquirida del pasado y dirigido al conocimiento para actuar y prever tenía hondas raíces, visibles en las primeras expresiones de la literatura popular surgida en el interior de Europa.

En el Decir de las siete virtudes, obra literaria aparecida hacia 1407 y de autoría de Francisco Imperial, las cuatro virtudes cardinales (justicia, fortaleza, prudencia y templanza), así como las tres teologales (caridad, fe y esperanza), se vuelven tema de la poesía vernácula.

Como literato, Imperial fue admirador de Dante (GIMENO 1987, p. 211) y no solo siguió la tendencia racionalista abierta en la época por Tomás de Aquino, sino que renovó los simbolismos: incluyó pecados representados en forma de bestias que se contraponían a las virtudes. A la prudencia contrapuso Asyssyna, sierpe "que nunca cata donde pone sus pisadas, ni quiere ver donde dan las pasadas". "Esta bestia representa", se ha afirmado, "la inconsideración; es decir, la falta de recto juicio" (WOODFORD 1954, p. 288).

Posteriormente, durante el auge de la Contrarreforma, con su condena a toda heterodoxia, no se vio en ella, ni siquiera en España, forma alguna de herejía. En la ciudad de Huesca, España, en 1647, es impresa la obra de Baltasar Gracián que llevó por título Oráculo manual y arte de prudencia. En palabras de su censor, al dar cuenta de ella a la autoridad real, no dudó en recomendarla como "epítome de aciertos del vivir, pues lo es en lo sentencioso y en lo conciso" (GRACIÁN 1725, Censura).

Alonso Muñoz de Otalora, de la orden de los clérigos menores, en la aprobación que otorgó a la obra, señaló que la misma era útil en "el modo de gobernarse un político prudente, no solo para conservarse en el puesto, y asegurar los aciertos en él, sino para evitar los riesgos, y caso de aver sucedido los daños, el reparo dellos (sic)". Respecto al orden y armonía entre piedad cristiana y racionalismo, declaró que, a pesar de ser oráculo, era "enseñanza que no disuena a nuestra fe, antes bien, por tan conforme a razón, anivelada a sus verdades, con que no hay donde peligre el lector, sí donde halle seguro puerto el discreto" (GRACIÁN 1725, Censura).

En el apartado intitulado "Vivir a la ocasión", Baltasar Gracián dio muestra de su conocimiento de Emblemata, la obra de Andrea Alciato, publicada en 1534 en París, en la que la prudencia fue representada con cabeza de Jano bifronte, en tanto que ocasión y agudeza son descritas calva la primera y con escamas la segunda (SELIG 1956, p. 4-6). En su obra, Gracián consignó una expresión que puede tomarse como objetivo central de su esfuerzo literario y pedagógico: "Ai algunos tan paradóxamente impertinentes", indica, "que pretenden que todas las circunstancias del acierto se ajusten a su manía, y no al contrario. Mas el sabio sabe", concluye, "que el norte de la prudencia consiste en portarse a la ocasión" (GRACIÁN 1725, p. 294). Esta afirmación encaja perfectamente con las pretensiones didácticas reconocidas en la prudencia y plasmadas a manera de emblema por otro intelectual de la época: Johann Amos Comenius.

En su obra, Orbis sensualium pictus, ese teólogo, filósofo y pedagogo moravo, incluye, hacia 1643, grabados en madera en calidad de lecciones, 
aunque de autoría aún indeterminada (FIJAŁKOWSKY 2010, p. 15). Entre la variedad de artes, industrias, plantas, animales, materias y cosas que ilustra (y emplea como medio didáctico para la enseñanza), la prudencia encontrará, como se muestra en la imagen siguiente, su lugar como emblema.

Imagen 6:

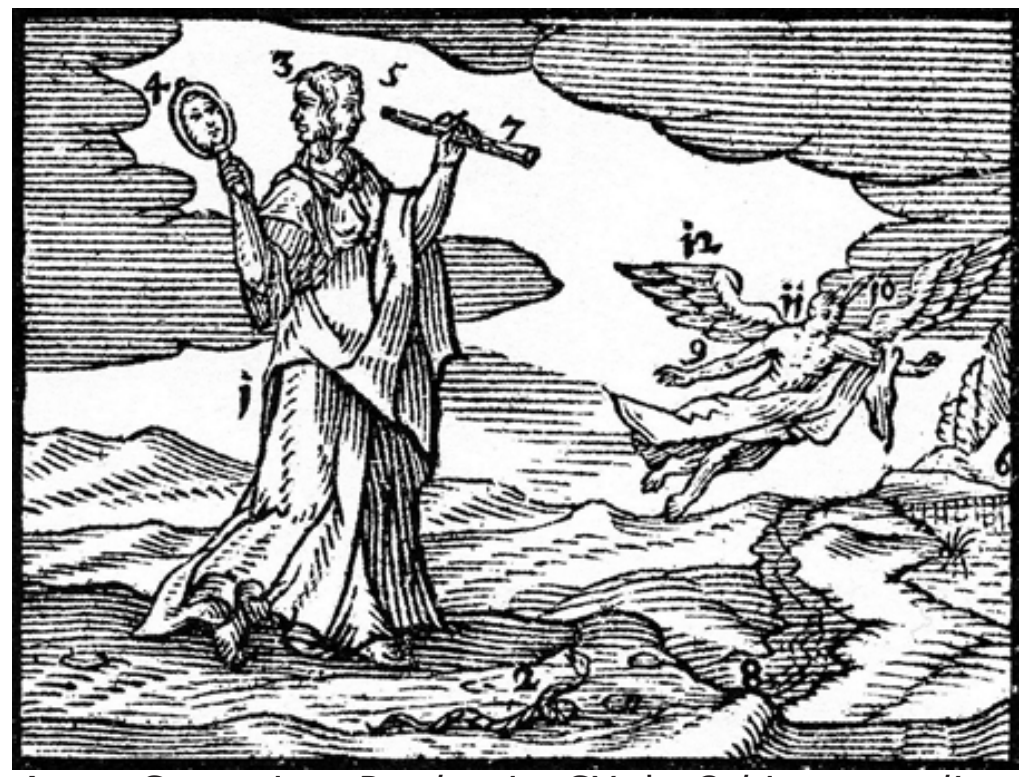

Johann Amos Comenius. Prudentia. CX de Orbis sensualium pictus.

Versión latín-alemán, Nuremberg, Alemania, 1669.

Comenius explica puntualmente cada uno de los elementos de la representación, los mismos que enumera, logrando con ello una dimensión didáctica, así como sinóptica, fácil a la memorización y útil a la retención por los sentidos. La prudencia "contempla todas las cosas a su alrededor como una serpiente", en tanto que "mira hacia atrás como con un espejo a lo pasado, viendo ante sí como con telescopio a lo venidero". En la imagen, la prudencia "ve también lo que ha hecho, y lo que todavía está por hacer" en tanto que utiliza "los medios dispuestos para alcanzar sus fines" $y$, con ello, aprovechar la "ocasión, que tiene frente hirsuta y nuca calva, y que con sus alas fácilmente escapa" (COMENIUS 1669, p. 228-229).

La historia es entonces donde se realiza la operación por cuyo efecto "la prudencia mira hacia atrás como un espejo a lo pasado"; es ella quien conserva y almacena las experiencias $y$, por consiguiente, es a ella que se recurre para traerlas al presente, actualizarlas y ponerlas al servicio del prudente. Esa visión a un tiempo retrospectiva y prospectiva es lo que asemeja la prudencia con el Jano bifronte, quien conociendo lo pasado puede atisbar el futuro. De ahí que las experiencias inmortalizadas por la historia en los libros latinos se entendieran aplicables a contextos culturales tan distantes, geográfica y culturalmente, como, por ejemplo, la España del siglo XVII. Precisamente de ahí se retomará a continuación un caso significativo, que permitirá mostrar en todo su esplendor el funcionamiento de la prudencia en la historiografía en su calidad de sistema de comprensión racional, pragmático, consciente de su ingénita dimensión ética y fundamentado en la solidez de la experiencia. 


\section{Nihil novum sub sole}

El 15 de mayo de 1596, Antonio de Herrera y Tordesillas fue nombrado por Felipe II Cronista Mayor de Indias. La intención real fue la de que, "habiendo sido tan grandes y dignas de consideración en la memoria de las gentes, las cosas sucedidas en el descubrimiento de las Indias, pacificación y población de ellas", se debía tener memoria de los hechos de los conquistadores, así como de "las costumbres, ritos y antigüedades que por tradición, desde los tiempos de la gentilidad de los indios, se pudiesen saber" (Archivo General de Indias [AGI] 1595, f. 508). El monarca ordenó a Herrera que "bien y fielmente haréis la dicha historia, procurando averiguar la verdad en todo lo que esta hubiere, de modo que salga muy cierta y guardaréis secreto en las cosas que se encargaren y debas guardar".

Entre las cosas que se le encargaron y debió guardar, consta la elaboración de un texto, en el que, a manera de ensayo, el Cronista Mayor elaboró una reflexión que intituló "Discurso y tratado sobre que el medio de la historia es suficiente para adquirir la prudencia". Este escrito, junto con otros discursos, fue otorgado en custodia al procurador del convento de los Carmelitas Descalzos de Madrid, hacia 1631, después de la muerte de Herrera (HERRERA 1804, p. V). A continuación se describirán sus argumentos, poniendo especial énfasis en los lineamientos, tanto historiográficos como epistemológicos, que definió, ejemplificando finalmente el carácter utilitario del conocimiento y la razón pragmática que empleó para operar sus propios razonamientos históricos.

Al inicio de su disertación, afirma el cronista real, que "de poco sirven los trabajos de los historiadores sino van encaminados a fin que se pueda conseguir de ellos el principal provecho de su lectura, que es la prudencia, virtud que da siempre a los hombres materia para ejercitarse y forma a la felicidad" (HERRERA 1804 , p. 21). Para Antonio de Herrera, la prudencia asemeja al arte, sin dejar de ser "hija de la razón, virtud intelectual y dada al hombre para su defensa".

Herrera sentencia que para constituirla se necesitan tres partes: "la primera, la memoria de las cosas pasadas; la segunda, el conocimiento de las presentes; la última el echar de ver las venideras; en lo cual muestra principalmente la prudencia su fuerza y en ella da su verdadero fruto" (HERRERA 1804, p. 22). La previsión del futuro "en ninguna manera se puede conseguir", afirma el cronista, "sin que derive de las dos primeras".

Quien desee entonces alcanzar este genio "deberá considerar con mucho cuidado todo lo sucedido en los tiempos pasados, y comparándolo con lo presente, y conociendo en que parte corresponde a sus obras, y en que son diferentes de ello, aprenderá", apunta, "el verdadero arte de entrever el fin de las acciones humanas". La historia es fundamento de la prudencia porque "son muchas y muy varias las cosas particulares que se han de conocer". Por ello, no basta solo la experiencia del individuo, "con solas las cosas que él mismo ve y trata, y por esto podrá adquirir con dificultad esta ciencia de bien vivir tan necesaria en todo tiempo y a todos estados" (HERRERA 1804, p. 23).

Según el cronista real, se consigue tanto fruto de la historia, "porque de los muchos y varios acontecimientos que en ella se hallan, se saca con la 
experiencia el verdadero gusto del bien y el mal". Y a partir de este preciso punto, tributa Antonio de Herrera en su tratado reverencia a los emblemas característicos de la prudencia, al afirmar: "Y si no fuera mucha prolijidad traer varios ejemplos, mostrara en la historia como en un espejo el retrato de cada virtud" (HERRERA 1804, p. 24).

Las lecciones de historia permiten, siguiendo esa lógica, "que a un hombre ningún caso le parezca nuevo, ni le perturbe ningún accidente, sino que se muestre tal, que con el conocimiento de los sucesos humanos haya aprendido a proveer a todas las cosas que haya antevisto". Por ello conviene, según el cronista, que "vaya el hombre formando en sí mismo una cierta regla general de las acciones particulares, que no es otra cosa sino la prudencia, mediante la cual, podamos gobernar a nosotros mismos y a la república" (HERRERA 1804, p. 32).

Es importante destacar que en el español del Siglo de Oro, "accidente" y "ocasión" pueden utilizarse casi como sinónimos. "Accidente" denota en la época "un caso no proveído ni pensado, un suceso inopinado y casual" (REAL ACADEMIA ESPAÑOLA 1726, p. 41). La argumentación vertida permite finalmente a Herrera concluir que "[...] en suma, como la prudencia es principio de toda buena operación, así se puede decir que es la historia casi un principio de donde deriva la misma prudencia" (HERRERA 1804, p. 25).

Más allá de lo vertido en su tratado, resulta relevante conocer el dominio material y pragmático donde la prudencia pudo servir a Antonio de Herrera como "principio de toda buena operación". En los documentos resguardados en el registro archivístico, existe evidencia de los procedimientos historiográficos seguidos por el Cronista Mayor de Indias: siguiendo la lógica interpretativa dictada por la prudencia, aplicó las experiencias transmitidas por la historia para significar comportamientos de agentes históricos que él mismo indagó.

En cumplimiento del encargo real, al iniciar la primavera de 1601, Antonio de Herrera vio terminada su historia general del descubrimiento y población del Nuevo Mundo por los súbditos de la corona de España (HERRERA 1601). Sin embargo, por disposiciones de un miembro de la corte, los ejemplares fueron retenidos en la imprenta, con lo que se impidió su venta y circulación. Un apretado escrito de ocho fojas, firmado por Francisco Arias Dávila y Bobadilla, conde de Puñonrostro, hizo saber a la autoridad real las razones de dicha medida: divergencias del suscriptor con respecto a las afirmaciones plasmadas por el Cronista Mayor en su historia. El quejoso, miembro del Consejo de Guerra del rey, expresó que "habiendo visto las décadas de la historia de las Indias, que Antonio de Herrera, cronista de vuestra Majestad tiene escritas, en lo que trata de Pedrarias Dávila, mi abuelo", fueron escritas "cosas indignas de historia tan grave y de lo que merecen sus servicios, hechos en España y en las Indias" (AGI s.f.(a), f. 1).

Al llegar a la parte medular de la denuncia, donde se narra lo más destacado del año de 1516 en Tierra Firme, el conde recrimina una expresión del cronista, quien al dar cuenta de una presunta reconciliación planeada por su abuelo, el conquistador Pedrarias Dávila, con su archirrival, Basco Núñez de Balboa, consigna que el primero, "fiel o fingidamente, para más conformación de amistad, trató de casarle con su hija mayor doña María", quien vivía en España. 
La expresión "fiel o fingidamente" resultó insultante al conde, que afirma en su escrito que "todos los que le trataron en las Indias, que sin pasión hablan de este casamiento, han dicho la llaneza y verdad con que le trató Pedrarias, y lo que deseó favorecer y socorrer a Basco Núñez en todas las formas que pudo" (AGI s.f. (a), f. 3r. párrafo 28). Herrera tuvo acceso al escrito y anotó al margen, para su defensa, lo siguiente: "El cronista anduvo bien en decir fiel o fingidamente porque no se pudo saber el ánimo de Pedrarias y más viendo lo que después sucedió, de cortarle la cabeza" (AGI s.f. (a), f. 3r. parr. 28).

Herrera publicó posteriormente la respuesta a tal acusación, señalando la lógica prudente que había guiado su interpretación, pues en todo tiempo "el cronista imitó a Tito Livio, que dice estas mismas palabras en el casamiento de Julia con Pompeyo, por medio del cual se confederaron" (AGI s.f. (b), f. 10). En pocas palabras, al calificar como "fiel o fingidamente" el matrimonio procurado por el abuelo del conde, Herrera procedió volviendo (como Jano) su rostro hacia las experiencias comunicadas por la historiografía antigua, reconoció como ante el espejo el carácter universal de la ambición humana, actualizando la forma en que Pompeyo, mucho tiempo antes que Pedrarias, había dispuesto los mismos medios para acometer semejante fin.

En ese sentido, "no hay nada nuevo bajo el sol". Por diferente que sea la circunstancia, siendo los hombres hechos iguales por Dios, sus anhelos y pasiones son los mismos: los casos que transmite la historia, el conocimiento de la naturaleza humana y el reconocimiento de los medios disponibles advierten del presente y ayudan a prever el futuro. "Para hacer esto conviene que la historia nos presente, cualquier suceso", señaló Herrera, "vestido de sus causas y de todos aquellos accidentes que le acompañan, porque sin la causa de tales particulares no se puede llegar a la universal conclusión, que es el verdadero principio de obrar con razón cierta" (HERRERA 1804, p. 31).

\section{Camino a la Selva Negra}

La popularidad de la prudencia se propagó por toda Europa más allá de la filosofía y la literatura, abarcando ámbitos como la plástica. Pintores de la talla de Luca Jordanus o grabadores como Nicolás Vani mantuvieron su cultivo hasta bien entrado el siglo XVIII. En este último campo, la prudencia se reprodujo no sólo en la obra de los grandes maestros, sino, como dan cuenta las múltiples representaciones anónimas existentes, también en objetos domésticos que caracterizaron al Renacimiento e incluso en el tarot.

Si se acepta que el concepto renacentista de prudencia fue predominantemente ciceroniano (CAPE JR. 2003, p. 61), se puede ver en el virtuosismo discursivo de la retórica una razón de su decadencia como sistema de conocimiento. Si hacia 1669 Baltazar Gracián recordaba con entusiasmo: "las serpientes son maestras de toda sagacidad; ellas nos muestran el camino de la prudencia" (GRACIÁN 1725, p. 325); Thomas Hobbes rechazará "la prudencia como epistemológicamente insuficiente y percibirá su eficacia práctica como quimérica" (ALTMAN 1986, p. 316). De esa manera, con el paso de los años, intelectuales como Edmund Burke se verán decepcionados, señalando que, así 
como "hay una sabiduría valiente; hay una prudencia falsa, reptil; el resultado, no de la cautela sino del miedo" (BURKE 1804, p. 53).

El predominio paulatino del cartesianismo y la difusión del movimiento ilustrado propiciaron una etapa de repliege de la prudencia como sistema de conocimiento práctico que, por cuestiones de espacio, será imposible describir detalladamente. De hecho, la prudencia se vio asociada al mero "proceso sin fin de la elaboración de ensayos, que en la tarea de percibir los objetos más claramente, argumentó continuamente evidencia inadmisible y creció con ello indistinta a su objeto original" (ALTMAN 1986, p. 316). La historia no quedará exenta del contagio racionalista que sobrevendría a la postre, volviéndose en casos positivos una disciplina plural (en cuanto a la recepción de técnicas y metodologías), pero afectándose seriamente por una especialización tal que no le permitirá ser apta para solucionar problemas individuales de orientación, de carácter cotidiano o socialmente relevantes.

Muchos científicos sociales han vuelto a considerar la historia como un saber capaz de restituir el vínculo que una vez se tuvo con los problemas prácticos. Las posiciones más conservadoras han propuesto que "quizá la mejor manera de crear una ciencia social unitaria con un lenguaje común sería que todos los científicos sociales tuvieran un fundamento en historia" (ELSTER 2010, p. 202). Otros sugieren "favorecer la emergencia de una ciencia social unificada, en la que la historia sería una sociología histórica del pasado y la sociología una historia social del presente" (CHARLE; ROCHE 2002, p. 16). Cualesquiera de las dos tendencias demanda resolver los contrasentidos de la razón moderna y "en lugar de construir los valores humanos simplemente como un problema de ética individual o moral en la creación de conocimientos confiables acerca del mundo social, es más útil concebirlos", afirma Lee, "como parte integral de una ciencia social histórica, cuya misión fundamental en nuestro tiempo debería ser imaginar y evaluar futuros posibles y formas de lograrlos" (LEE 2005, p. 18).

Es tarea aún pendiente determinar hasta qué grado pudo Heidegger intuir la estrecha relación que alguna vez, bajo la égida de la prudencia, unió a la historia con la razón pragmática. En 1928, inició el filósofo una nueva cátedra en la Universidad de Friburgo y con ella quizá la etapa más sobresaliente de la tradición filosófica del siglo XX. Si bien la semilla plantada en su seminario "Sobre la frónesis" no fue cultivada posteriormente como respuesta a los contrasentidos éticos de la razón moderna, germinó después, dando origen a otros campos temáticos. Hans-Georg Gadamer se refiere a dicho seminario "como uno de los acontecimientos decisivos en su desarrollo intelectual" (BERNSTEIN 1991, p. 230), al grado de señalar, respecto a la frónesis, que "la principal labor de la filosofía es justificar esa forma de razón contra el dominio de la tecnología basado en la ciencia" (GADAMER 1975, p. 316).

Hoy queda muy poco espacio para reflexionar sobre esa forma de conocimiento, pues "vivimos en una época donde las condiciones requeridas para el ejercicio de la frónesis, la aceptación compartida de principios universales y leyes, han caído por su propio peso" (BERNSTEIN 1985, p. 286). Sin embargo, también hay quien reconozca en ella "una contribución potencialmente 
valiosa" para el entendimiento de la nueva función de la ciencia y para lograr "el fortalecimiento de un sentido más significativo de la frónesis en la era posmoderna" (TAYLOR 1996, p. 102).

\section{Referencias bibliográficas}

ARCHIVO GENERAL DE INDIAS. Nombramiento de Antonio de Herrera como cronista mayor de Indias. Indiferente, no 425, e. 28. Aceca: 1596

. Argumentos del conde de Puñonrostro contra la Historia General de Herrera. Patronato, no 172, e. 19, b. 18. Madrid: s. f. (a).

Pro defensione veritatis. Patronato, e. 19, b. 7. Valladolid: s.f (b).

ARISTOTLE. Nichomachean Ethics. Indianapolis: Hacklett, 1985.

ALTMAN, B. Joel. Rhetoric, Prudence, and Skepticism in the Renaissance by Victoria Kahn. Renaissance Quaterly, V. 2, no 39, p. 314-317, 1986.

AQUIN, Thomas. Summae theologicae. II-II, Disponible en: http://www. corpusthomisticum.org/sth3047.html\#40981. Consultado el: 20 mar. 2012.

BERNSTEIN, Richard J. From Hermeneutics to Praxis. In: HOLLINGER, Robert (ed.). Hermeneutics and Praxis. Notre Dame: University of Notre Dame Press, 1985. p. 272-296.

Perfiles filosóficos. México: Siglo XXI Editores, 1991.

BIEMEL, Walter. Heidegger. Reinbek bei Hamburg: Rowohlt Taschenbuch, 1973.

BREWER, Gary. The challenges of interdisciplinarity. Policy Sciences, no 32, p. 327-337, 1999.

BURKE, Edmund. Maxims and opinions. London: C. Whittingham, 1803. V. 1.

CAPE JR., Robert W. Cicero and the Development of Prudential Reasoning at Rom. In: HARIMANN, Robert. Prudence: Classical Virtue, Postmodern Practice. Pennsylvania: Pennsylvania State University Press, 2003.

CICERO, Marco Tulio. De inventione, Paris: Les Belles Lettres, 1994.

CHANCELLOR, Philippe de. Summa de bono. Berna: Franke, 1985.

CHARLE, Christophe; ROCHE, Daniel. Pierre Bourdieu et I'histoire. Le Monde, Paris, 06 de fev. 2002, p. 16.

DINGJAN, Fr. Discretio: Les Origens patristiques et monastiques de la doctrine sur la prudence chez saint Thomas d'Aquin. Assen: Van Gorcum, 1967.

EDGERTON, Samuel Y. Giotto und die Erfindung der dritten Dimension. München: Wilhelm Fink, 2003.

ELSTER, Jan. One Social Science or Many? In: UNESCO-International Social Science Council. World Social Science Report. 2010. Paris: UNESCO, 2010, p. 199-200. 
FIJAŁKOWSKY, Adam. Vortrag zur Eröffnung der Ausstellung "Orbis Pictus". In: RITZI, Christian (org.). Mitteilungsblatt des Förderkreises Bibliothek für Bildungsgeschichtliche Forschung. n० 21, Berlin, p. 15-21, 1 Mai 2010.

GADAMER, Hans-Georg. Hermeneutics and Social Science. Cultural Hermeneutics, no 2, p. 307-316, 1975.

GAUTHIER, R. A.; JOLIF, J. L'Ethique à Nicomaque, Louvain: Publications Universitaires, 1970. T. 1.

GIBBONS, Michael. La nueva producción del conocimiento. Barcelona: Pomares-Corredor, 1997.

GRACIÁN, Baltazar. Obras de Lorenzo Gracián, Amberes: Casa de Gerónimo y Juan Bautista Verdussen, 1669. T. I.

. Oráculo manual y arte de prudencia. Amberes: Casa de Juan Bautista Verdussen, 1725.

GUILLAUD, Jacqueline. Giotto. Architekt der Farben und Formen. Freskenzyklus der Arena-Kapelle in Padua. Stuttgart: Klett Cotta, 1988.

HANET, David P. Aesthetics and Ethics in Gadamer, Levinas, and Romaticism: Problems of Phronesis and Thecne. PMLA, V.1, no 114, p. 32-45, enero 1999.

HERRERA, Antonio de. Historia general de los hechos de los castellanos en las islas i Tierra Firme del mar océano. Madrid: Imprenta Real, 1601. Discursos morales, políticos e históricos inéditos de don Antonio de Herrera, Madrid: Imprenta de Ruiz, 1804. T. 1.

HIRSCH HADORN, Gertrude. The Emergence of Transdisciplinarity as a Form of Research. In: HADORN, Gertrude Hirsch (org.). Handbook of Transdisciplinary Research. Berlin: Springer, 2008.

KANT, Immanuel. Kritik der praktischen Vernunft. Hamburg: Meiner, 2003.

KARLQVIST, Anders. Going beyond disciplines. The meaning of interdisciplinarity. Policy Sciences, no 32, p. 379-383, 1999.

LEE, Richard E. Ciencias Sociales y políticas sociales: de los dilemas nacionales a las oportunidades mundiales. La Plata / Montevideo: UNESCO, 2005.

LOTTIN, Odon. Les debuts du traité de la prudence au moyen âge. Louvain: Abbaye du Mont César, 1932.

LUCKNER, Andreas. Klugheit. Berlin: De Gruyter, 2005.

MACKITTERICK, David. Print, Manuscript and the Search for Order, 14501830. Cambridge: Cambridge University Press, 2003.

MAGNUS, Albertus. Opera Omnia. Müster: Aschendorff, 1968-1972. 
MCQUADE, Paula. "A Labyrinth of Sin": Marriage and Moral Capacity in Thomas Heywood's "A Woman Killed with Kindness". Modern Philology, V. 98, no 2, p. 231-250, noviembre 2000.

OTFRIED, Höffe. Aristoteles' universalistische Tugendethik. In: RIPPE, KlausPeter; SCHABER, Peter (orgs.). Tugendethik. Stuttgart: Reclam, 1998. p. $42-68$

PANOFSKY, Erwin. Meaning in the visual arts. Doubleday: Anchor Press, 1955.

PAYER, Pierre J. Prudence and the Principles of Natural Law: A Medieval Development. Speculum, V. 1, no 54, p. 55-70, enero 1979.

PLATO. Platons Werke. Berlin: Friedrich D. E. Schleiermacher Editor, 1861.

RAND, E. K. Cicero in the Courtroom of St. Thomas Aquinas. Milwaukee: Marquette University Press, 1946.

REAL ACADEMIA ESPAÑOLA, Diccionario de la lengua castellana, T. 1. Madrid: Imprenta de la Real Academia, 1726.

STRIDBECK, CarlGustaf. Bruegelstudien. Untersuchungen zu den ikonologischen Problemen bei Pieter Bruegel. Stokholm: Almquist \& Winksell, 1956.

TAYLOR, Chales Alan. Defining Science: A Rhetoric of Demarcation. Madison: University of Wisconsin Press, 1996.

THEODOR, Ebert. Phronêsis. Anmerkungen zu einem Begriff in der Nikomachischen Ethik (VI 5, 8-13). In: HÖFFE, Otfried (Org.): Aristoteles. Nikomachische Ethik. Berlin: Akademie Verlag, 2006.

WALLERSTEIN, Immanuel. Summary of Open the Social Sciences. Social Science Research Council, n. 50, v. 1, p. 1-7.

WeStBeRG, Daniel. Right Practical Reason: Aristotle, Action, and Prudence in Aquinas. Oxford: Clarendon Press, 1994.

WINTERBOTTOM, Michael. De Oratore, Orator, Brutus. In: REYNOLDS, L. D. Texts and Transmissions: A Survey of the Latin Classics. Oxford: Clarendon Press, 1983. p. 102-109

WOODFORD, Archer. Edición crítica de Dezir de las cuatro virtudes de Francisco Imperial. Nueva Revista de Filología Hispánica, no 8, p. 268-294, 1954. ZIRPOLO, Lilian H. Ave Papa, Ave Papabile. The Sacchetti Family, Their Art Patronage, and Political Aspirations. Toronto: CRRS, 2005. 